Reviews: Methods and Technologies in Fish Biology

\title{
and Fisheries
}

2009, Volume 9, Part I, Part 3, Pages 181-193

http://dx. doi.org/10.1007/978-1-4020-9640-2 11

(c) 2009 Springer

The original publication is available at http://www.springerlink.com

\section{Effects of T-bar and DST Tagging on Survival and Growth of European Hake}

\author{
Aurélie Jolivet $^{1, *}$, Hélène de Pontual , François Garren ${ }^{1}$, Marie-Laure Bégout ${ }^{2}$ \\ ${ }^{1}$ Ifremer, Laboratoire de Sclérochronologie des Animaux Aquatiques STH/LASAA, Z.I. Pointe du diable, BP 70, \\ F-29280 Plouzané, France. \\ ${ }^{2}$ Ifremer, UMR 6217 CRELA CNRS-IFREMER-Univ. De La Rochelle, place du séminaire, BP 5, F-17137 \\ L'Houmeau, France \\ *: Corresponding author: A. Jolivet, Tel.: +33 298224 964; fax: +332 98224 653. email address: \\ ajolivet@ifremer.fr
}

\begin{abstract}
:
Controlled experiments were conducted to assess the effects of T-bar and DST tagging on postrelease survival and growth of European hake. In this study, two groups of each 30 hake were considered: small fish (SF, average total length: $29.9 \mathrm{~cm} \pm 2.2 \mathrm{~cm}$ ) and large fish (LF, average total length: $36.4 \mathrm{~cm} \pm 2.5 \mathrm{~cm})$. Within each size group, fish were randomly assigned to one of 3 treatment groups: control (C), T-bar tagging referred as conventional tagging (CT) and DST tagging (DST) with dummy tags. After 4 months, the overall survival rate was $35 \%$. Smaller fish were less impacted by the stress induced by handling, anaesthesia and tagging and in the SF group, the survival rates were similar (30\%) for CT or DST. Specific growth rates were highly variable and no significant difference could be observed between control and tagged fish. Our results demonstrate that (1) conventional tagging affects fish survival rates and (2) DST tagging is feasible in the field on "small fish" with expected survival rate and recapture probability close to that of conventional tagging.
\end{abstract}

Keywords: Merluccius merluccius - Archival tag - Husbandry - Midterm experiment - Captive hake 
European hake, Merluccius merluccius, is a demersal fish widely distributed from the west coast of Norway, south to the coast of Mauritania, and eastwards into the Mediterranean Sea. It is a major demersal resource in the North East Atlantic, which has been heavily exploited by fisheries. Total landings of M. merluccius have decreased from 120000t in the early 1960s to 50000t in recent years. Although there is no evidence that multiple populations exist, the northern stock (ICES areas IIIa, IV, VI and VII and VIIIa, b, d) and the southern stock (ICES areas VIIIc and IXa) are managed separately (ICES 2005).

Recent mark-recapture experiments (de Pontual et al. 2003; Pineiro et al. 2007) have provided evidences of growth underestimation of the species due to a bias in the age estimation method internationally agreed and routinely used for the species (de Pontual et al. 2006). Simulations have estimated a significant associated impact on assessment (e.g. higher F, lower SSB) and management advices (Bertignac and de Pontual 2007). Besides growth, directed movements and fishing mortality are other key information that can be gained from mark-recapture experiments (Beverton and Holt 1957). To estimate fishing mortality, it is necessary to estimate post release mortality due to the stress of capture, handling and tagging on the fish (Brattey and Cadigan 2004). Estimating post-release mortality is difficult and requires experiments that compare the survival of tagged fish vs. control fish held in captivity (Rutecki and Meyers 1992; Millner et al. 1993; Pierce and Tomcko 1993). Furthermore, it is now well recognized that fish tagged with archival tags (also called Data Storage Tags, DST) provide important information about fish movements, behaviour and their environmental conditions (Thorsteinsson 2002). As such internal tagging is more invasive and expensive than external T-bar tagging (referred below as conventional tagging), a feasibility study needed to be conducted before the start of a DST tagging experiment in the field on European hake. 
The main challenge to study the effects of conventional tagging on mortality rates in European hake is that this species is not commercially farmed. One reason for this might well be that the species has long been regarded as especially sensitive to capture- and handlingrelated damages. A pioneering study on larval rearing experiment (Bjelland and Skiftesvik 2006) provided some basic information on egg incubation to weaned larvae. Here we report a study carried out on wild-caught fish kept in captivity. The main objectives were to estimate the effects of conventional and DST tagging on fish survival and growth. The information gained from these research objectives will help determine the feasibility of DST tagging studies at sea.

\section{Methods}

\section{Fish origin}

Fish were caught in the Bay of Biscay in July 2005 using the capture method developed by de Pontual et al. (2003) for mark-recapture experiments. To acclimatize the fish, individuals were kept in captivity for 7 months in $15 \mathrm{~m}^{3}$ tanks. These tanks were supplied with seawater flow at ambient temperature (from $7.9^{\circ} \mathrm{C}$ to $13.7^{\circ} \mathrm{C}$ ), flushed with a daily water renewal rate of $20 \%$, and illuminated following the natural photoperiod. Fish were fed ad libitum on inert preys (sprat, herring and mackerel).

\section{Tagging protocol}

Prior to tagging the experimental group of fish (average total length: $31.2 \mathrm{~cm} \pm 2.3 \mathrm{~cm}$ and average weight: $190.1 \mathrm{~g} \pm 52 \mathrm{~g}$ ), we determined the best anaesthesia protocol suitable for further experiments onboard research vessels. Our protocol criteria were the following: low toxicity for both operator and fish, short induction time, short recovery time, small secondary 
effects, and no withdrawal period. After testing several protocols, we choose Benzocaïne (ethyl $p$-aminobenzoate) at a concentration of $100 \mathrm{mg} \mathrm{l}^{-1}$ at a sea water temperature of $9.3^{\circ} \mathrm{C}$. The tagging experiment started on February 7, 2006 and ended on June 15, 2006 (128 day duration). Two size groups were selected: small fish (SF, average total length TL \pm standard deviation SD: $29.9 \mathrm{~cm} \pm 2.17 \mathrm{~cm}, \mathrm{~N}=30$ ) and large fish (LF, average total length TL $36.4 \mathrm{~cm}$ $\pm 2.5 \mathrm{~cm}, \mathrm{~N}=30$ ). Within each size group, fish were randomly assigned to 3 treatment groups: control (C), conventional tagging (CT) and DST tagging (DST).

All fish were anaesthetised, measured (total length $\mathrm{TL}_{0}$ ) and weighed $\left(\mathrm{W}_{0}\right)$ prior to subsequent treatment. SF individuals were exposed to a $100 \mathrm{mg} \mathrm{l}^{-1}$ benzocaïne solution, a concentration which was increased to $120 \mathrm{mg} \mathrm{l}^{-1}$ for the LF group. Total exposure time to benzocaïne did not vary between groups and was set at 15 min to allow for the time needed to insert DST tags (5 min). Individual fish behaviour such as loss of reaction to external stimuli and loss of equilibrium, was followed during the anaesthesia steps. Conventional tagging (CT group) was carried out according to the method developed by de Pontual et al. (2003) for mark recapture experiment. Briefly, a T-bar tag was inserted at the base and in front of the second dorsal fin and the fish was injected with a solution of oxytetracycline at a dose of 60 mg $\mathrm{kg}^{-1}$ of fish. This antibiotic is used to mark calcified structures for age validation (de Pontual et al. 2006). In addition, the DST fish group had Star-Oddi DST micro dummy tags (8.3 mm diameter x $25.4 \mathrm{~mm}$ length, $3.7 \mathrm{~g}$ in air), inserted in the peritoneal cavity. This surgerical procedure consisted of 1) $1 \mathrm{~cm}$ cut through the ventral muscle at $1 \mathrm{~cm}$ in front of the anus, 2) pushing the tag gently inside the peritoneal cavity and 3) suturing the wound by 2-3 stitches with polyamide monofilament (Bégout Anras et al. 2003). After treatment, fish were transferred to two $15 \mathrm{~m}^{3}$ indoor tanks, one for the SF group (thus including 3 groups: SF-C, SF-CT, SF-DST) and the second for the LF group (LF-C, LF-CT, LF-DST). At the end of the experiment fish were killed with an overdose of anaesthetic and measured (total length 
112

113

114

115

116

117

118

119

120

121 where $\mathrm{W}_{\mathrm{t}}$ is the weight of the fish at time $\mathrm{t}$ and $\mathrm{W}_{\mathrm{e}}$ is the theoretical weight calculated from

122 the length-weight relationship derived from the field: $W_{e}(g)=0.00513 \mathrm{~L}^{3.074}$ (Dorel 1986).

123 Specific Growth Rate (SGR \% day ${ }^{-1}$ ) was calculated as:

124

125

126

127 where $\left.\mathrm{g}=\left[\ln \left(\mathrm{W}_{\mathrm{tf}}\right)-\ln \left(\mathrm{W}_{\mathrm{t} 0}\right)\right] /\left(\mathrm{t}_{\mathrm{f}}-\mathrm{t}_{0}\right)\right]$ and $\mathrm{W}_{\mathrm{tf}}$ and $\mathrm{W}_{\mathrm{t} 0}$ are the wet body weight $(\mathrm{g})$ at death or

128 experimental end $\left(\mathrm{t}_{\mathrm{f}}\right)$ and tagging $\left(\mathrm{t}_{0}\right)$ time respectively (Houde and Schekter 1981;

129 Nordgarden et al. 2003). Estimates of individual growth rate were not available for the control

130

131

132

133

134

135

136

$\mathrm{TL}_{\mathrm{f}}$ ), weighed $\left(\mathrm{W}_{\mathrm{f}}\right)$ and sexed. Euthanized and fish dead during the course of the experiment were deep frozen prior subsequent treatment.

The condition factor of individual fish was calculated as (Wege and Anderson 1978; Jobling et al. 2001):

$\mathrm{K}_{\mathrm{t}}=\mathrm{W}_{\mathrm{t}} / \mathrm{W}_{\mathrm{e}} \mathrm{X} 100$

(Eqn 1)

(Eqn 2)

$\operatorname{SGR}=\left(e^{\mathrm{g}}-1\right) \times 100$ 
138 where $\mathrm{W}_{\text {DST }}$ is the DST weight in air and $\mathrm{W}_{0}$ the fish wet weight. Two groups were 139 considered: $\mathrm{R} 1$ with $\mathrm{R}<2 \%$ and $\mathrm{R} 2$ with $\mathrm{R} \geq 2 \%$ (Winter 1983).

140 Measurements of length, weight and SGR expressed as average \pm standard deviation (SD),

141 were compared using ANOVA or t-tests with treatments and group size as factors after data

142 had been tested for normality. Estimates of condition factors were compared using Kruskal-

143 Wallis test (KW). Survival analysis was conducted using Kaplan-Meier analysis with respect

144 to treatment and group size. However, as the initial condition $\left(\mathrm{K}_{0}\right)$ impacts fish survival, we 145 also applied Cox regression analysis with $\mathrm{K}_{0}$ as covariable. Spearman's rank correlation was 146 used to test the relationship between an individual's initial condition factor and survival rate. 147 Statistical analyses were performed using SPSS 14.0. (SPSS, USA) and the significance level 148 was set at $\mathrm{P}<0.05$.

\section{Results}

\section{Analysis of initial fish characteristics according to treatment and group size}

152 At the end of the acclimation period, $68 \%$ of fish had an initial condition factor (Kt0) greater 153 than $100 \%$. Thus, we considered that acclimazation to rearing conditions had been achieved 154 for most individuals after 7 months. At the beginning of the experiment, Kt0 ranged from $71 \%$ to $127 \%$ and three $\mathrm{Kt} 0$ classes $(<80 \%, 80-100 \%$ and $>100 \%)$ were considered for each 
162

Out of the initial 60 fish, 21 were survived until the end of the experiment (day 128), which corresponds to an overall survival rate of 35\%. Kaplan-Meier survival functions with respect to treatments (C, CT and DST) and size groups (SF and LF) showed that, regardless of fish size, tagging (CT or DST) severely decreased survival probability compared to the control group (Figure 1). Mortality was observed 50 days after tagging and after this time period mortality stabilized in at least the SF group. It is worth noting that, for both SF and LF groups, survival proportion did not differ significantly between CT and DST groups (Log Rank tests: SF: $\mathrm{P}_{\mathrm{C} / \mathrm{CT}}=0.017, \mathrm{P}_{\mathrm{C} / \mathrm{DST}}=0.07, \mathrm{P}_{\mathrm{CT} / \mathrm{DST}}=0.777 ; \mathrm{LF}: \mathrm{P}_{\mathrm{C} / \mathrm{CT}}=0.021, \mathrm{P}_{\mathrm{C} / \mathrm{DST}}=0.003$, $\left.\mathrm{P}_{\mathrm{CT} / \mathrm{DST}}=0.705\right)$. Moreover, it is worth noting that no mortality has been observed in anaesthetized groups during the preliminary experiment after 24 days.

[Figure 1 here]

The initial condition Kt0 had a clear effect on the survival rate of fish. The seven tagged fish that had a $\mathrm{Kt} 0<80$, all died within the first 28 days. The correlation between survival time and Kt0 was significant when all tagged fish were considered (Spearman correlation test, $\mathrm{N}=40$, $\mathrm{P}=0.006$ ), whereas no significant correlation was observed if fish with a Kt0 $\leq 80$ were removed from the statistical analysis. Cox regression analysis (Figure 2) indicated that DST tagging may slightly decrease the survival probability compared to conventional tagging.

\section{[Figure 2 here]}

The R ratio also affected survival rate. Survival differed significantly between R1 and R2 (Log Rank tests: $\mathrm{P}_{\mathrm{R} 1 / \mathrm{R} 2}=0.023$ ) and actually, all fish with $\mathrm{R}>2 \%$ died rapidly after tagging (Figure 3). 
[Figure 3 here]

\section{Effect of tagging on growth}

191 Determining the effects of tagging on fish growth was limited by two factors. First, survival at

192 the end of the experiment was low for tagged groups (CT, DST), especially for the LF group

193 (Figure 1). Second, the control fish were not tagged. The total masses of SF_C group were 194 $1804.5 \mathrm{~g}$ and $2813.0 \mathrm{~g}$ at the start and the end of experiment, respectively. The survival time

195

[Table 2 here]

Statistical analysis of the tagged groups revealed relatively high individual growth variability regardless of the size and treatment group (Table 2). Negative SGR were observed for fish that had a very poor initial condition and died rapidly after tagging (Figure 4a). It is worth noting that one fish in poor initial condition survived until the end of the experiment (Figure 4). Comparisons of SGR between control and treatment fish showed that tagging did not significantly affect the SGR (t-tests, $\mathrm{df}=9, \mathrm{P}_{\mathrm{SF}_{-} \mathrm{CT}}=0.145, \mathrm{P}_{\mathrm{SF} \_\mathrm{DST}}=0.117, \mathrm{P}_{\mathrm{LF}_{-} \mathrm{CT}}=0.197$, $\left.\mathrm{P}_{\text {LF_DST }}=0.346\right)$.

Progressive feeding resumption occurred after 7 days post tagging. It started at a low level (0.5 prey day ${ }^{-1}$ per fish) and then increased to 1 prey day ${ }^{-1}$ per fish. The first week post tagging could thus be considered as a critical period characterized by fasting and death of fish that had poor initial condition. 
[Figure 4 here]

214

\section{Discussion}

\section{Effect of tagging on survival}

217 Anaesthetics doses applied to European hake during our experiments (100-120 mg l-1), 218 correspond to the upper limit of those reported for other species (Soivio et al. 1977; Iwama et al. 1989; Iversen et al. 2003). Considering the required doses and deep anaesthesia induction time, hake seems to be relatively resistant to anaesthesia.

The first fact to be considered is that handling and anaesthesia might well be more harmful than expected from the short term (24 days) preliminary experiment as the mortality rate reached 30\% in control group. The different mortality rates observed in the LF and SF groups also suggests that the former is more sensitive (40\% against $20 \%$ for LF and SF respectively). We hypothesize that poor initial condition is a factor limiting survival for some fish, although direct evidence is missing because control fish were not individualized. The low ambient 227 temperature $\left(9^{\circ} \mathrm{C}\right)$ at the beginning of the experiment may have also been partly responsible 228 for difficult recovery. Actually subsequent pilot tests have demonstrated that winter is not the best period for supplying experimental facilities with wild hake (de Pontual et al. unpublished data).

In terms of conventional tagging, survival rate was 30\% for small tagged fish against $70 \%$ for

232 the control group. These results confirm the observations made on controls regarding the 233 higher ability of small fish to resist to physical stress. These results also indicate that, the CT tagging process has a strong effect on survival probability. This could be explained both by species-specific response and a sub-optimal tagging protocols. However, several studies have demonstrated negative effects of tag application to wild and hatchery fish on survival, in 
particular on salmon (Saunders and Allen 1967; Isaksson and Bergman 1978; Hansen 1988;

238 Moffett et al. 1997; Crozier and Kennedy 2002). Another important consideration is the 239 duration of the experiment. Two periods can be distinguished in terms of the fish mortality 240 rates. The first mortality phase extended to about 50 days post tagging (handling and tagging 241 effects), whereas the second phase occurred at the end of the experiment (fish probably died 242 due to nutritional stress because of unsuccessful feeding resumption, see below). Such a result 243 questions the reliability of short term experiments, which may well provide biased estimations 244 of mortality. This is the case for very short term (2-5 days) experiments held on research 245 vessel during tagging surveys (e.g. de Pontual et al. 2003 for European hake). This issue has 246 also been emphasised for short term (5-10 days) experiments in submersible enclosures 247 (Brattey and Cadigan 2004). To best estimate port-release mortality rates for tagged fish, 248 individual fish must be observed for longer periods of time.

249 A higher mortality rate in DST tagged fish than CT fish could result from the invasive surgery. Surprisingly survival probabilities in DST and CT fish were similar at least in small 251 fish. The removal of a probable $\mathrm{Kt}_{0}$ effect only slightly decreased the survival probability. 252 However, the tag to body weight ratio (R) has an effect on hake survival. This is in 253 accordance with earlier work showing higher mortality and/or reduced swimming 254 performance in DST-tagged fish (Marty and Summerfelt 1986; Greenstreet and Morgan 1989; 255 Peake et al. 1997; Adams et al. 1998). Our results confirm that this ratio should not be greater 256 than 2\% (Stasko and Pincock 1977; Winter 1983) even if the question is challenged (Jepsen et 257 al. 2005). Based on the hake length-weight relationship (Dorel 1986), Star-Oddi DST micro 258 tags should not be placed on a body wet weight less than $180 \mathrm{~g}$, which corresponds to a total 259 length of approximately $30 \mathrm{~cm}$. 
262 Food resumption started only 7 days post-tagging and progressively increased after this 263 period. Food consumption remained low relative to fish in other stocking tanks until c.a. 100 264 days post tagging. Consequently, we can hypothesize that fish first experienced a weight loss

265 phase due to fasting. This assumption is supported by a strong negative SGR of fish that died 266 early in the experiment. The recovery process may have been longer than in nature as mark267 recapture results indicated that fish stopped growing for 20-50 days after release (de Pontual 268 et al. 2006). This might relate to upset feeding behaviour as hake acclimation on inert preys 269 had proved to be a challenging process. It may also explain the difference observed in the 270 growth rates estimated in this study $\left(0.013 \pm 0.016 \mathrm{~cm} \mathrm{~d}^{-1}\right)$ and estimates obtained from field 271 experiment (up to $0.054 \pm 0.004 \mathrm{~cm} \mathrm{~d}^{-1}$ for fish which had one year or more at liberty; de 272 Pontual et al. 2006). An important outcome of the present work is that growth did not differ 273 significantly between control and tagged fish. This result corroborates the findings of 274 previous works on species such as European sea bass (Bégout Anras et al. 2003), juvenile cod 275 (Jensen 1967; Tranquilli and Childers 1982; Svåsand et al. 1990; Cote et al. 1999), and adult 276 cod (Righton et al. 2006). The latter concluded that tagging had no long term effect on growth 277 except on the gonads mass, where tags could potentially occupy the space for gonad growth 278 (Righton et al. 2006).

\section{Conclusion}

281 In this study, the first estimates of post tagging mortality were established and these results 282 suggest mortality after tagging might be high in field experiments. They have to be refined 283 before mark-recapture data can be used to estimate exploitation rates and population sizes. 284 Our results also suggest that improvements in tag implantation could increase post tagging 285 survival rate. Contrary to initial predictions, similar survival rates were observed for fish 286 tagged with DST and conventional tags. Recovery rate close to that of conventional tagging 
can reasonably be expected. Results also emphasize the need for a thorough fish selection prior to DST tagging based on fish size and initial condition. Small fish with a high initial condition would be the most suitable for future tagging studies in the field. Actually, criteria derived from this experiment have provided suitable basis for a successful field pilot study which analysis is ongoing (de Pontual et al. unpublished data).

\section{Acknowledgements}

The authors are thankful to M. Suquet for his help during experiment and fruitful discussion on hake rearing. Furthermore, we thank H. Arrizabalaga, N. Jepsen, I. Quincoces and an anonymous referee for their reviews and B. Graham for improving the language. This study was conducted under the approval of the Animal Care Committee of France under the official licence of M.L. Bégout (17-010).

\section{References}

Adams N.S., Rondorf D.W., Evans S.D., Kelly J.E. and Perry R.W. (1998) Effects of surgically and gastrically implanted radio transmitters on swimming performance and predator avoidance of juvenile chinook salmon (Oncorhynchus tshawytscha). Can. J. Fish. Aquat. Sci. 55(4), 781-787.

Bégout Anras M.L., Covès D., Dutto G., Laffargue P. and Lagardère F. (2003) Tagging juvenile seabass and sole with telemetry transmitters: medium-term effects on growth. ICES J. Mar. Sci. 60(6), 1328-1334.

Bertignac M. and de Pontual H. (2007) Consequences of bias in age estimation on assessment of the northern stock of European hake (Merluccius merluccius) and on management advice. ICES J. Mar. Sci. 64(5), 981-988. 
Beverton R.J.H. and Holt S.J. (1957) On the dynamics of exploited fish populations. London, 533 pp.

Bjelland R.M. and Skiftesvik A.B. (2006) Larval development in European hake (Merluccius merluccius L.) reared in a semi-intensive culture system. Aquacult. Res. 37(11), 1117-1129.

Brattey J. and Cadigan N. (2004) Estimation of short-term tagging mortality of adult Atlantic cod (Gadus morhua). Fish. Res. 66(2-3), 223-233.

Cote D., Scruton D.A., Cole L. and McKinley R.S. (1999) Swimming performance and growth rates of juvenile Atlantic cod intraperitoneally implanted with dummy acoustic transmitters. N. Am. J. Fish. Manag. 19(4), 1137-1141.

Crozier W.W. and Kennedy G.J.A. (2002) Impact of tagging with coded wire tags on marine survival of wild Atlantic salmon (Salmo salar, L.) migrating from the R. Bush, Northern Ireland. Fish. Res. 59(1-2), 209-215.

de Pontual H., Bertignac M., Battaglia A., Bavouzet G., Moguedet P. and Groison A. (2003) A pilot tagging experiment on European hake (Merluccius merluccius): methodology and preliminary results. ICES J. Mar. Sci. 60(6), 1318-1327.

de Pontual H., Groison A., Pineiro C. and Bertignac M. (2006) Evidence of underestimation of European hake growth in the Bay of Biscay, and its relationship with bias in the agreed method of age estimation. ICES J. Mar. Sci. 63(9), 1674-1681.

Dorel D. (1986) Poissons de l'Atlantique Nord-Est : relations taille-poids. Ifremer Report. DRV.86.001/RH/NANTES.

332 Greenstreet S.P.R. and Morgan R.I.G. (1989) The effect of ultrasonic tags on the growth rates of Atlantic salmon, Salmo salar L., parr of varying size just prior to smolting. $J$. Fish. Biol. 35(2), 301-309. 
Hansen L.P. (1988) Effects of carlin tagging and fin-clipping on survival of Atlantic salmon (Salmo salar, L.) released as smolts. Aquaculture 70(4), 391-394.

Houde E.D. and Schekter R.C. (1981) Growth rates, rations and cohort consumption of marine fish larvae in relation to prey concentrations. In: Lasker, $\mathrm{R}$ and Sherman, $\mathrm{K}$ (ed.) 2. ICES Symposium on the Early Life History of Fish, 2 Apr 1979, Woods Hole, MA (USA).

ICES (2005) Report of the Working Group on the Assessment of Southern Stocks of Hake, Monk, and Megrim (WGHMM). ICES CM 2005/ACFM:02.

Isaksson A. and Bergman P.K. (1978) An evaluation of two tagging methods and survival rates of different age and treatment groups of hatchery-reared Atlantic salmon smolts. J. Agric. Res. Icel. 10(2), 74-99.

Iversen M., Finstad B., McKinley R.S. and Eliassen R.A. (2003) The efficacy of metomidate, clove oil, Aqui-S registered and Benzoak as anaesthetics in Atlantic salmon (Salmo salar L.) smolts, and their potential stress-reducing capacity. Aquaculture 221(1-4), 549-566.

Iwama G.K., McGeer J.C. and Pawluck M.P. (1989) The effects of five fish anaesthetics on acid-base balance, hematocrit, blood gases, cortisol and adrenaline in rainbow trout. Can. J. Zool. 67(8), 2065-2073.

Jensen A.C. (1967) Effects of tagging on the growth of cod. Trans. Am. Fish. Soc. 96, 37-41.

Jepsen N., Schreck C., Clements S. and Thorstad E.B. (2005) A brief discussion on the 2\% tag/bodymass rule of thumb. In: Spedicato, MT, Lembo, G and Marmulla, G (ed.) Aquatic telemetry: advances and applications, FAO/COISPA, Rome, pp. 255-261.

Jobling M., Covès D., Damsgård B., Kristiansen H.R., Koskela J., Petursdottir T.E., Kadri S. and Gudmundsson O. (2001) Techniques for measuring feed intake. In: Houliham, 

49-87.

361

362

363

364

365

366

367

368

369

370

371

372

373

374

375

Marty G.D. and Summerfelt R.C. (1986) Pathways and mechanisms for expulsion of surgically implanted dummy transmitters from channel catfish. Trans. Am. Fish. Soc. 115(4), 577-589.

Millner R.S., Whiting C.L. and Howlett G.J. (1993) Estimation of discard mortality of plaice from small otter trawlers using tagging and cage survival studies. ICES-CM1993/G:24.

Moffett I.J.J., Crozier W.W. and Kennedy G.J.A. (1997) A comparison of five external marks for Atlantic salmon, Salmo salar L. Fish. Manage. Ecol. 4(1), 49-53.

Nordgarden U., Oppedal F., Taranger G.L., Hemre G. and Hansen T. (2003) Seasonnally changing metabolism in Atlantic salmon (Salmo salar, L.) I- Growth and feed conversion ratio. Aquacult. Nutr. 9(5), 287-293.

Peake S., McKinley R.S., Scruton D.A. and Moccia R. (1997) Influence of transmitter attachment procedures on swimming performance of wild and hatchery-reared Atlantic salmon smolts. Trans. Am. Fish. Soc. 126(4), 707-714.

Pierce R.B. and Tomcko C.M. (1993) Tag loss and handling mortality for northern pike marked with plastic anchor tags. N. Am. J. Fish. Manag. 13(3), 613-615.

Pineiro C., Rey J., de Pontual H. and Goni R. (2007) Tag and recapture of European hake (Merluccius merluccius L.) off the Northwest Iberian Peninsula: first results support fast growth hypothesis. Fish. Res. 88(1-3), 150-154.

Righton D., Kjesbu O.S. and Metcalfe J. (2006) A field and experimental evaluation on the effect of data storage tags on the growth of cod. J. Fish. Biol. 68(2), 385-400.

Rutecki T.L. and Meyers T.R. (1992) Mortality of juvenile sablefish captured by hand-jigging and traps. N. Am. J. Fish. Manag. 12(4), 836-837. 
Saunders R.L. and Allen K.R. (1967) Effects of tagging and of fin-clipping on the survival and growth of Atlantic salmon between smolt and adult stages. J. Fish. Res. Bd. Can. 24(12), 2595-2611.

Soivio A., Nyholm K. and Huhti M. (1977) Effects of anaesthesia with MS-222, neutralized MS-222 and benzocaine on the blood constituents of rainbow trout, Salmo gairdneri. J. Fish. Biol. 10(1), 91-101.

Stasko A.B. and Pincock D.G. (1977) Review of underwater biotelemetry, with emphasis on ultrasonic techniques. J. Fish. Res. Bd. Can. 34(9), 1261-1285.

Svåsand T., Jørstad K.E. and Kristiansen T.S. (1990) Enhancement studies of coastal cod in western Norway. Part I. Recruitment of wild and reared cod to a local spawning stock. ICES J. Mar. Sci. 47(1), 5-12.

Thorsteinsson V. (2002) Tagging methods for stock assessment and research in fisheries. Report of Concerted Action FAIR CT.96.1394 (CATAG). 79.

Tranquilli J.A. and Childers W.F. (1982) Growth and survival of largemouth bass tagged with Floy anchor tags. N. Am. J. Fish. Manag. 2(2), 184-187.

Wege G.J. and Anderson R.O. (1978) Relative weight $\left(\mathrm{W}_{\mathrm{r}}\right)$; a new index of condition for largemouth bass. In: Novinger, GD and Dillard, JG (ed.) New approaches to the management of small impoundments, American Fisheries Society, North Central Division, Special Publication 5, Bethesda, MD, pp. 79-91.

Winter J.D. (1983) Underwater biotelemetry. In: Nielsen, LA and Johnson, DL (ed.) Fisheries Techniques, American Fisheries Society, Bethesda, MD, pp. 371-395. 
407 Table 1: Percentage of fish with an initial condition factor (Kt0) in each size group and the 408 average value of $\mathrm{Kt}_{0}(\%)$ ( \pm standard deviation SD \%) with respect to each size group (SF and 409 LF) and treatment group (C: control, CT: conventional tag, DST: data storage tag).

\begin{tabular}{lllccc}
\hline & & \multicolumn{2}{c}{ Group } & \\
\cline { 3 - 4 } & & & Small fish & Large fish & Total \\
\hline Treatment & control & Kt0 $<80 \%$ & 0 & 20 & 10 \\
& & Kt0 $80-100 \%$ & 10 & 20 & 15 \\
& Kt0 $>100 \%$ & 90 & 60 & 75 \\
& Total & $\mathbf{1 0 0}$ & $\mathbf{1 0 0}$ & $\mathbf{1 0 0}$ \\
& Average Kt0 \pm SD & $105.2( \pm 6.7)$ & $100.3( \pm 15.5)$ & $102.7( \pm 11.9)$ \\
& Kt0 $<80 \%$ & 10 & 30 & 20 \\
& Kt0 80-100\% & 30 & 10 & 20 \\
& Kt0 $>100 \%$ & 60 & 60 & 60 \\
& Total & $\mathbf{1 0 0}$ & $\mathbf{1 0 0}$ & $\mathbf{1 0 0}$ \\
& Average Kt0 $\pm \mathrm{SD}$ & $99.2( \pm 11.9)$ & $96.1( \pm 16.7)$ & $97.7( \pm 14.2)$ \\
& Kt0 $<80 \%$ & 20 & 10 & 15 \\
& Kt0 80-100\% & 10 & 20 & 15 \\
& Kt0 $>100 \%$ & 70 & 70 & 70 \\
& Total & $\mathbf{1 0 0}$ & $\mathbf{1 0 0}$ & $\mathbf{1 0 0}$ \\
& Average Kt0 $\pm \mathrm{SD}$ & $100.3( \pm 15.2)$ & $102.9( \pm 14.7)$ & $101.6( \pm 14.6)$ \\
\hline
\end{tabular}


410 Table 2: Growth characteristics with respect to size group (SF and LF) and treatment group

411 (CT: conventional tag, DST: data storage tag). SGR: specific growth rate (in $\%$ days $^{-1}$ ), $\mathrm{W}_{\mathrm{t} 0}$ :

412 initial weight $(\mathrm{g})$ and $\mathrm{W}_{\mathrm{tf}}$ : final weight $(\mathrm{g})$.

\begin{tabular}{|c|c|c|c|c|}
\hline Group _ treatment & & SGR & $\mathrm{W}_{\mathrm{t} 0}$ & $\mathrm{~W}_{\mathrm{tf}}$ \\
\hline \multirow{5}{*}{ SF_CT } & $\mathrm{N}$ & 10 & 10 & 10 \\
\hline & Mean & -1.7 & 174.6 & 181.9 \\
\hline & Standard deviation & 1.1 & 11.6 & 12.9 \\
\hline & Minimum & -9.7 & 95 & 129 \\
\hline & Maximum & 0.8 & 240 & 248 \\
\hline \multirow{5}{*}{ SF_DST } & $\mathrm{N}$ & 10 & 10 & 10 \\
\hline & Mean & -0.7 & 195 & 214.6 \\
\hline & Standard deviation & 0.5 & 13.9 & 28.8 \\
\hline & Minimum & -4.1 & 110 & 97 \\
\hline & Maximum & 0.7 & 256 & 443 \\
\hline \multirow{5}{*}{ LF_CT } & $\mathrm{N}$ & 10 & 10 & 10 \\
\hline & Mean & -0.3 & 314.7 & 304.2 \\
\hline & Standard deviation & 0.3 & 21 & 23.8 \\
\hline & Minimum & -2.6 & 212 & 196 \\
\hline & Maximum & 0.2 & 423 & 415 \\
\hline \multirow{5}{*}{ LF_DST } & $\mathrm{N}$ & 10 & 10 & 10 \\
\hline & Mean & -0.1 & 325.1 & 320.7 \\
\hline & Standard deviation & 0.1 & 27.8 & 32.3 \\
\hline & Minimum & -0.6 & 196 & 190 \\
\hline & Maximum & 0.2 & 503 & 520 \\
\hline \multirow{5}{*}{ Total } & $\mathrm{N}$ & 40 & 40 & 40 \\
\hline & Mean & -0.7 & 252.4 & 255.4 \\
\hline & Standard deviation & 0.3 & 14.4 & 15.4 \\
\hline & Minimum & -9.7 & 95 & 97 \\
\hline & Maximum & 0.8 & 503 & 520 \\
\hline
\end{tabular}




\section{Figure legends}

415

416 Figure 1: Kaplan Meier survival functions for (A) small fish (SF) and (B) large fish (LF).

417 Control (dotted line), Conventional tagging (dashed line), DST tagging (solid line).

418

419 Figure 2: Survival functions with respect to fish size and tagging method derived from the 420 Cox regression with initial condition factor as a covariate. Small Fish - Conventional Tagging 421 (SF-CT, solid line), Small Fish - DST Tagging (SF-DST, dotted line), Large Fish 422 Conventional Tagging (LF-CT, dashed line), Large Fish - DST Tagging (LF-DST, dash423 dotted line).

424

425 Figure 3: Survival functions of DST tagged fish for different tag to fish weight ratios (R) 426 derived from Cox regression with initial condition factor as covariate. $\mathrm{R}<2 \%$ (solid line), $427 \quad \mathrm{R} \geq 2 \%$ (dotted line).

428

429 Figure 4: Time distribution of Specific Growth Rates (SGR) estimated at fish death for 430 different fish size and tagging methods: Small Fish - Conventional Tagging (SF-CT, $\Delta$ ), 431 Small Fish - DST Tagging (SF-DST, ), Large Fish - Conventional Tagging (LF-CT, ×), 432 Large Fish - DST Tagging (LF-DST, o). SGR individual values are specified for fish that had 433 a particularly poor initial condition.

434 
$435 \quad$ Figure 1:

$436 \quad(\mathrm{~A})$

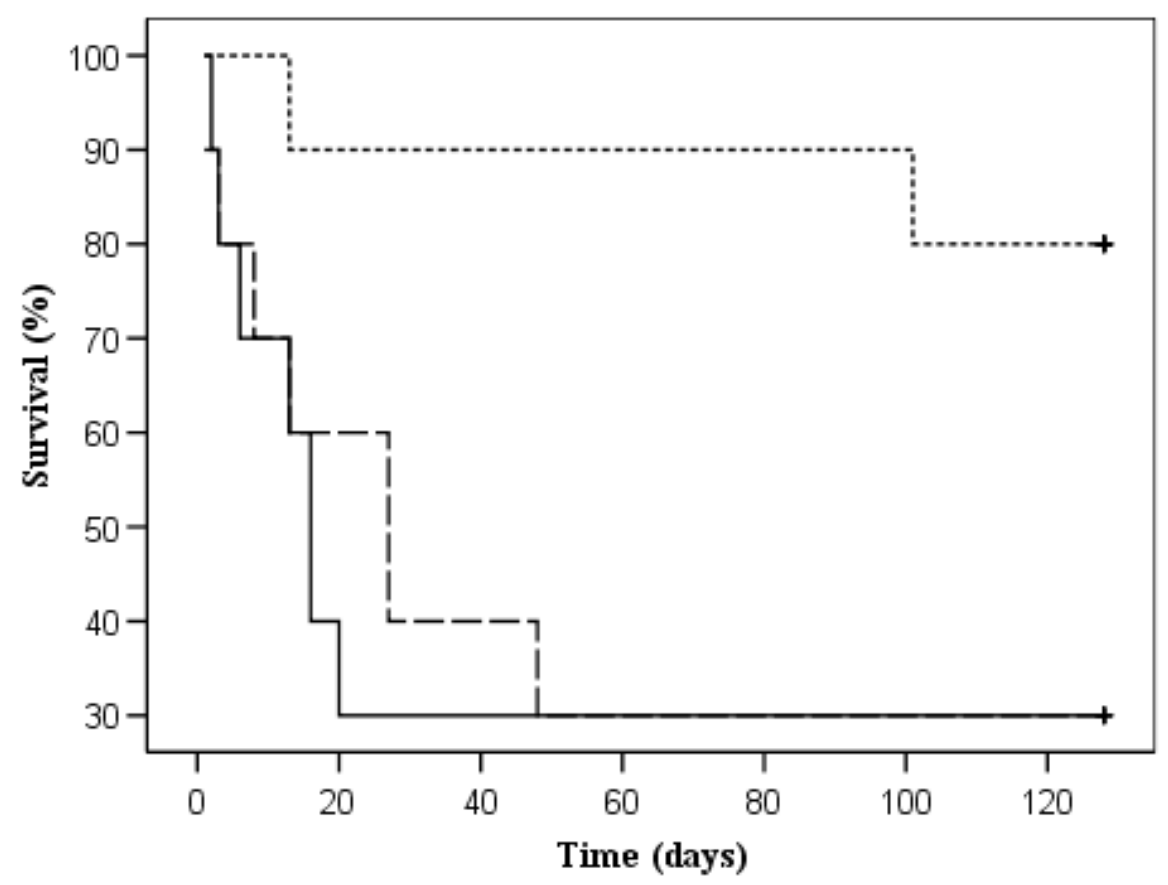

437

$438 \quad$ (B)

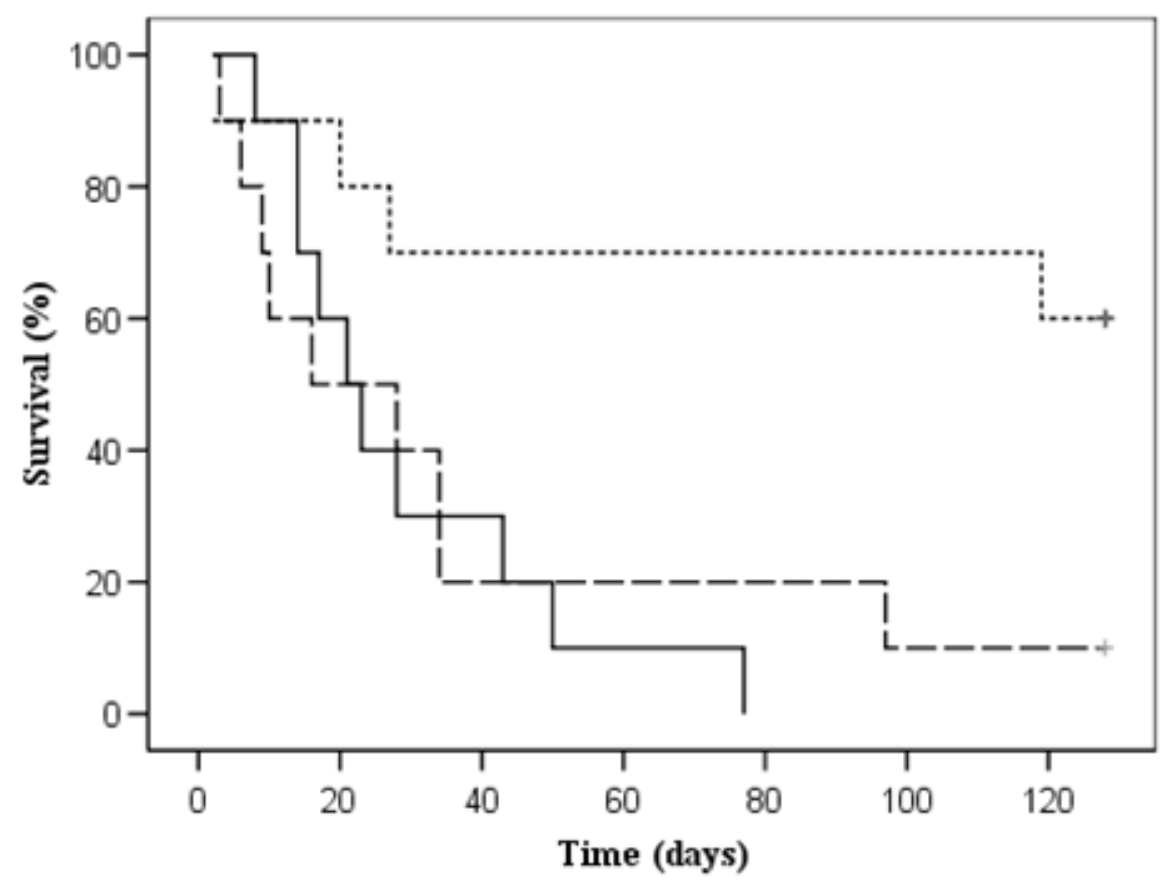

439 
Figure 2:

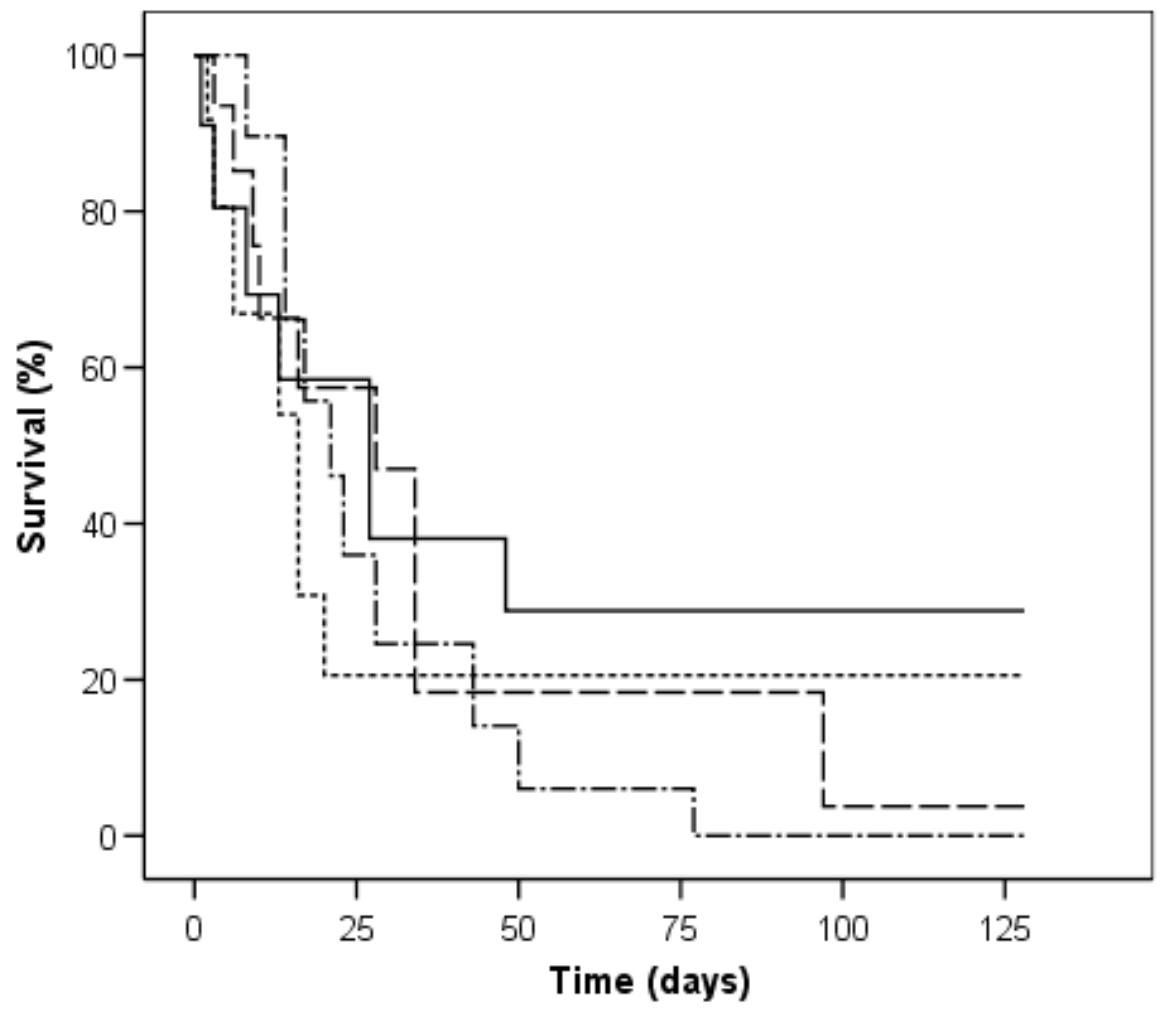

441 
442 Figure 3:

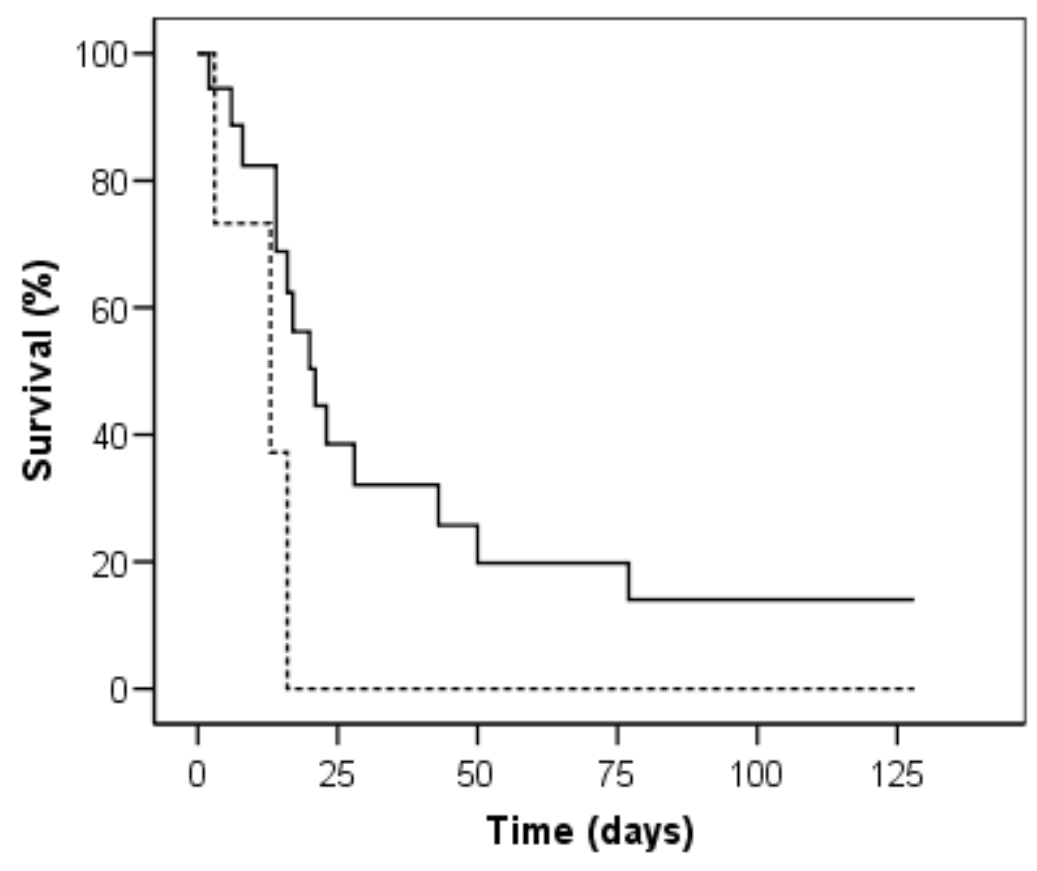

443 
Figure 4:

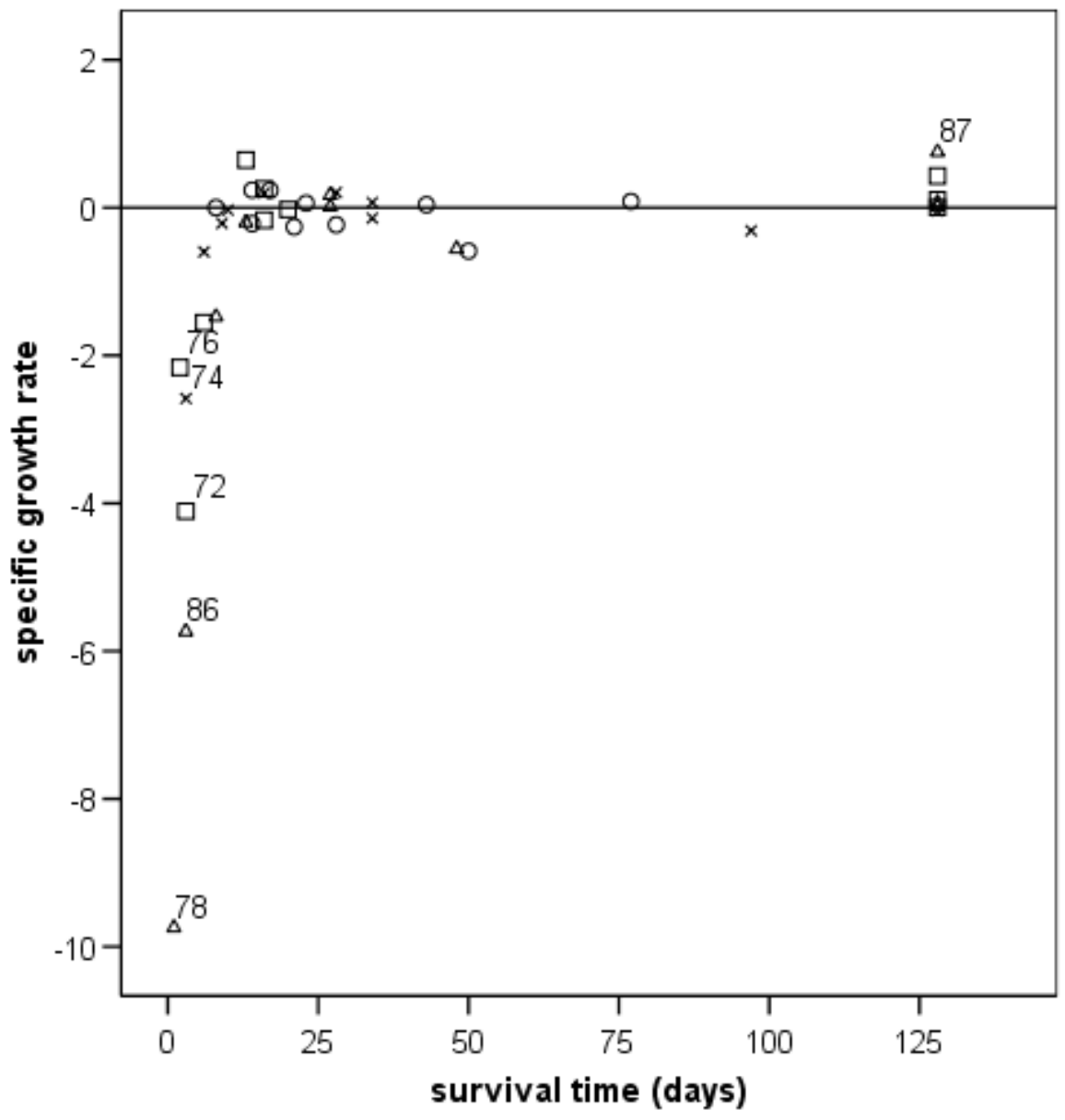

445 